\title{
PENGARUH PENGGUNAAN TANAH MEDITERAN SEBAGAI BAHAN SUBSTITUSI SEMEN TERHADAP KUAT TEKAN DAN TARIK BETON
}

\author{
Sri Devi Nilawardani \\ Jurusan Teknik Arsitektur, Fakultas Teknik, Universitas Hasanuddin, \\ J1. Poros Malino Km.6, Bontomarannu, Kabupaten Gowa, Sulawesi Selatan \\ Email: sridevinilawardani04@gmail.com
}

\begin{abstract}
Abstrak
Beton merupakan suatu bahan komposit (campuran) dari semen, agregat halus, agregat kasar dan air. Potensi batu kapur di Indonesia sangat besar yaitu mencapai 28,678 milyar ton yang merupakan bahan utama dalam pembuatan semen dan sewaktu-waktu dapat menipis karena merupakan sumber daya alam yang tidak dapat diperbaharui. Jadi, untuk mengurangi pemakaian batu kapur diperlukan pemanfaatan tanah Mediteran sebagai pengganti sebagian semen dalam pembuatan beton. Gagasan awal berpedoman pada unsur kimia yang terkandung dalam tanah Mediteran yang hampir sama dengan semen, yaitu karbonat $(\mathrm{CaO})$ dan silica $\left(\mathrm{SiO}_{2}\right)$. Tujuan dari penelitian ini yaitu mengungkapkan pengaruh substitusi tanah Mediteran sebesar 20\% dan 40\% terhadap kuat tekan dan tarik beton pada umur 3, 7, 14 dan 28 hari dengan jumlah benda uji masing-masing 3 buah pada setiap variasi dalam silinder $10 \mathrm{~cm} \times 20 \mathrm{~cm}$ dengan perencanaan campuran beton mengacu pada metode SK SNI T-15-1900-03. Jenis penelitian yang digunakan adalah kuantitatif dengan metode eksperimental yakni uji laboratorium dan analisis data metode komparatif dan regresi. Hasil penelitian menunjukkan bahwa kuat tekan dan kuat tarik beton yang menggunakan substitusi tanah Mediteran dapat menyaingi kekuatan beton normal dengan perawatan kering. Pada komposisi 20\% tanah Mediteran menurun sebesar 51.35\% atau hanya 7.9 $\mathrm{MPa}$ (kuat tekan) dan 30.60\% atau hanya $0.93 \mathrm{MPa}$ (kuat tarik belah). Sedangkan komposisi 40\% tanah Mediteran menurun sebesar $43.78 \%$ atau hanya $9.13 \mathrm{MPa}$ (kuat tekan) dan $2.24 \%$ atau hanya 1.31 MPa (kuat tarik belah).
\end{abstract}

Kata kunci: tanah Mediteran, kuat tekan, kuat tarik, dry curing.

\section{Abstract \\ Title:The Effect of Using Mediteran Soil as Cement Substitution Materials in Compressive Strength and Tensile Strength of Concrete}

Concrete is a composite material (mixture) of cement, fine aggregate, coarse aggregate, and water. The potential of limestone in Indonesia is very large, reaching 28.678 billion tons which is the main ingredient in the cement manufacture. In the long run it will be depleted because it is a non-renewable natural resources. So to reduce the use of limestone the utilization of Mediteran soil as a substitution for some cement in the manufacture of concrete is required. The initial idea is based on the chemical composition contained in the Mediteran soil almost identical to the cement, which is carbonate $(\mathrm{CaO})$ and silica ( $\mathrm{SiO} 2)$. The purpose of this research is to reveal the influence of substitution of Mediteran soil by $20 \%$ and $40 \%$ in the compressive strength and tensile of the concrete at age 3, 7, 14, and 28 days with the number of test specimen each 3 pieces on each variation in $10 \mathrm{~cm} x 20 \mathrm{~cm}$ cylinder with planning of concrete mixture refers to SK SNI method T15-1900-03. The type of research used is quantitative with the experimental method of laboratory test and data analysis of comparative method and regression. The results show that compressive strength and tensile strength of concrete using Mediteran soil substitution comparable to the strength of normal concrete with dry treatment. In the composition of $20 \%$ Mediteran soils decreased by $51.35 \%$ or $7.9 \mathrm{MPa}$ (compressive strength) and $30.60 \%$ or $0.93 \mathrm{MPa}$ (tensile strength). While the composition of $40 \%$ Mediteran soil decreased by $43.78 \%$ or $9.13 \mathrm{MPa}$ (compressive strength) and $2.24 \%$ or $1.31 \mathrm{MPa}$ (tensile strength).

Keywords: Mediteran soil, compressive strength, tensile strength, dry curing. 


\section{Pendahuluan}

Beton sebagai bahan bangunan sudah lama digunakan dan diterapkan secara luas oleh masyarakat sebab memiliki keunggulan-keunggulan dibanding material struktur lainnya, yakni memiliki kekuatan yang baik, tahan api, tahan terhadap perubahan cuaca, serta relatif mudah dalam pengerjaan. Bahan - bahan campuran beton adalah semen, air dan agregat. Agregat dapat berupa kerikil, batu pecah, sisa bahan mentah tambang, agregat ringan buatan, pasir atau bahan sejenis lainnya (Samekto dan Rahmadiyanto, 2001). Terkadang, satu atau lebih bahan tambah ditambahkan untuk menghasilkan beton dengan karakteristik tertentu, seperti kemudahan pengerjaan (workability), durabilitas, dan waktu pengerasan (McCormac, 2000).

Tinggi rendahnya kinerja beton tergantung pada karakteristik material penyusunnya dan bahan tambah yang digunakan. Beberapa material tambahan secara efektif mampu meningkatkan kinerja beton, setelah melalui pengujian di berbagai tingkatan atau kategori dan dinilai memenuhi standar yang ditetapkan termasuk pertimbangan ekonomi bahkan sosial, telah diproduksi secara massal. Maka dari itu, salah satu bahan alternatif yang diajukan adalah tanah Mediteran.

Tanah Mediteran ini digunakan sebagai bahan substitusi dalam pembuatan beton karena walaupun potensi batu kapur di Indonesia sangat besar dan hampir merata di seluruh Indonesia, jumlahnya mencapai 28,678 milyar ton dengan perincian 61,376 juta ton sebagai cadangan terunjuk (probable) dan 28,616 juta ton sebagai cadangan terka (Tushadi Madiadipoera, Direktorat Sumber
Daya Mineral, 1990). Sama seperti halnya dengan batu bara, minyak bumi dan gas alam, batu kapur merupakan sumber daya yang tidak dapat diperbaharui. Banyak dilakukan penambangan batu kapur secara besarbesaran oleh industri, salah satunya adalah industri semen di Indonesia.

Batu kapur adalah salah satu bahan utama dalam pembuatan semen. Dalam hal ini kita harus mencari bahan alternatif pengganti batu kapur apabila sewaktu-waktu cadangan batu kapur di Indonesia mulai menipis karena batu kapur merupakan sumber daya alam yang tidak dapat diperbaharui dan agar industri semen masih tetap dapat memproduksi semen.

Tanah Mediteran merupakan tanah yang bahan induknya berupa batuan beku yang berkapur atau batu gamping yang banyak mengandung karbonat dengan kadar $\mathrm{CaO}$ dan Silica $\left(\mathrm{SiO}_{2}\right)$ yang tinggi serta memiliki berat jenis yang terbilang rendah.

Pada penelitian ini, peneliti mencoba membuat beton dengan campuran berupa tanah Mediteran yang disubstitusi dalam penggunaan semen sebesar $20 \%$ dan $40 \%$ dalam pembuatan beton. Melalui penelitian ini diharapkan bahwa dengan menggunakan bahan tambah tanah Mediteran pada campuran semen mampu untuk mendapatkan campuran beton yang memiliki kuat tekan dan kuat tarik sesuai standar yang dapat digunakan dalam pembangunan dan membuat struktur aman atau setara dengan kekuatan beton yang menggunakan semen biasa agar dapat mengurangi penggunaan batu kapur secara masal. 


\section{Tinjauan Pustaka}

\section{Beton}

Menurut Samekto dan Rahmadiyanto (2001), dalam bidang bangunan yang dimaksud dengan beton adalah campuran dari agregat halus dan agregat kasar (pasir, kerikil, batu pecah atau jenis agregat lain) dengan semen yang dipersatukan oleh air dalam perbandingan tertentu. Beberapa faktor yang mempengaruhi kekuatan beton yaitu bahan-bahan campuran beton, cara-cara persiapan, perawatan dan keadaan pada saat dilakukan percobaan. Beton baik dalam menahan tegangan tekan daripada jenis tegangan yang lain, dan umumnya pada perencanaan struktur beton memanfaatkan sifat ini. Oleh karena itu, kekuatan tekan dari beton dianggap sifat yang paling penting dalam banyak kasus (Nugraha dan Antoni, 2007).

\section{Tanah Mediteran}

Tanah Mediteran merupakan tanah yang bahan induknya berupa batuan beku yang berkapur atau batu gamping yang banyak mengandung karbonat dengan kadar $\mathrm{CaO}$ dan Silica $\left(\mathrm{SiO}_{2}\right)$ yang tinggi serta memiliki berat jenis yang terbilang rendah. Kapur dalam tanah memiliki kandungan kalsium dan magnesium tanah. Hal ini terjadi karena keberadaan kedua unsur tersebut sering ditemukan berasosiasi dengan karbonat. Tanah kapur sebagai bahan utama pembuatan semen mengandung senyawa: Calsium Oksida $(\mathrm{CaO})$, Silika Oksida (SiO2), Aluminium Oksida (A12O3), Besi Oksida (Fe2O3) dan Magnesium Oksida (MgO).
Tabel 1. Komposisi tanah Mediteran

\begin{tabular}{|l|l|l|}
\hline No. & Senyawa & Berat (\%) \\
\hline 1. & $\mathrm{SiO}_{2}$ & 23,68 \\
\hline 2. & $\mathrm{Al}_{2} \mathrm{O}_{3}$ & 0,44 \\
\hline 3. & $\mathrm{Fe}_{2} \mathrm{O}_{3}$ & 0,15 \\
\hline 4. & $\mathrm{CaO}$ & 19,35 \\
\hline 5. & $\mathrm{MgO}$ & 0,018 \\
\hline 6. & $\mathrm{SO}_{3}$ & 1,66 \\
\hline 7. & $\mathrm{LOI}$ & - \\
\hline 8. & $\mathrm{Na}_{2} \mathrm{O}$ & 0,01 \\
\hline 9. & $\mathrm{~K}_{2} \mathrm{O}$ & 0,09 \\
\hline
\end{tabular}

Sumber : Muhammad Syarif, 2018

\section{Material Penyusun Beton}

1. Semen Portland

Semen adalah suatu jenis bahan yang memiliki sifat adhesif (adhesive) dan kohesif (cohesive) yang memungkinkan melekatnya fragmen-fragmen mineral menjadi suatu massa yang padat. Semen merupakan bahan yang jadi dan mengeras dengan adanya air dinamakan semen hidraulis (hydraulic cements). Semen portland atau biasa disebut semen adalah bahan pengikat hidroli berupa bubuk halus yang dihasilkan dengan cara menghaluskan klinker (bahan ini terutama terdiri dari silikat-silikat kalsium yang bersifat hidrolis), dengan batu gips sebagai bahan tambahan. Semen yang digunakan adalah Semen Portland Tipe I.

\section{Air}

Air adalah bahan dasar pembuatan beton. Air berfungsi untuk membuat semen bereaksi dan sebagai bahan pelumas antara butir-butir agregat. 
Untuk membuat semen bereaksi hanya dibutuhkan air sekitar 25-30 persen dari berat semen. Tetapi, pada kenyataan di lapangan apabila faktor air semen (berat air dibagi berat semen) kurang dari 0,35 maka adukan sulit dikerjakan, sehingga umumnya faktor air semen lebih dari 0,40 dimana terdapat kelebihan air yang tidak bereaksi dengan semen. Pada umumnya air minum dapat dipakai untuk campuran beton. Air yang mengandung senyawa-senyawa yang berbahaya, yang tercemar garam, minyak, gula atau bahan kimia lainnya, bila dipakai untuk campuran beton akan sangat menurunkan kekuatannya dan dapat juga mengubah sifat-sifat semen. Selain itu, air yang demikian dapat mengurangi afinitas antara agregat dengan pasta semen dan mungkin pula mempengaruhi kemudahan pengerjaaan (Nawy, 1998: 12).

\section{Agregat Halus}

Agregat halus (pasir) adalah mineral alami yang berfungsi sebagai bahan pengisi dalam campuran beton yang memiliki ukuran butiran kurang dari $5 \mathrm{~mm}$ atau lolos saringan no. 4 dan tertahan pada saringan no.200. Agregat halus (pasir) berasal dari hasil disintegrasi alami dari batuan alam atau pasir buatan yang dihasilkan dari alat pemecah batu (stone crusher). Agregat halus untuk beton dapat berupa pasir alam sebagai hasil disintegrasi alami dari batu-batuan atau berupa pasir buatan yang dihasilkan oleh alatalat pemecah batu. Agregat halus pada penelitian ini menggunakan jenis agregat halus yang pada umumnya berbutir halus, bulat-bulat akibat proses gesekan yaitu pasir alami yang berasal dari Bili-Bili, Kabupaten Gowa.

\section{Agregat Kasar}

Agregat kasar adalah agregat yang berukuran lebih besar dari $5 \mathrm{~mm}$, yang memiliki sifat kekuatan hancur dan ketahanan terhadap benturan yang dapat mempengaruhi ikatannya dengan pasta semen, porositas dan karakteristik penyerapan air yang mempengaruhi daya tahan terhadap proses pembekuan waktu musim dingin dan agresi kimia serta ketahanan terhadap penyusutan. Agregat kasar pada penelitian ini juga diambil dari pengikisan tepi maupun dasar sungai oleh air sungai yang mengalir (kerikil alami) di daerah Bili-Bili, Kabupaten Gowa.

\section{Kerangka Pikir}

Kerangka pikir merupakan model konseptual tentang bagaimana teori berhubungan dengan berbagai faktor yang telah diidentifikasi sebagai hal yang penting. Dengan demikian maka kerangka pikir adalah sebuah pemahaman yang melandasi pemahaman-pemahaman lainnya, sebuah pemahaman yang paling mendasar dan menjadi pondasi bagi setiap pemikiran atau suatu bentuk proses dari keseluruhan penelitian yang akan dilakukan (Sugiyono, 2006).

Dalam penelitian ini, konsep utamanya adalah memanfaatkan tanah Mediteran yang cukup melimpah di Kabupaten Jeneponto dengan baik dan hasil yang maksimal terhadap kuat tekan dan kuat tarik beton dari substitusi bahan tanah Mediteran dalam pembuatan beton. Tanah Mediteran ini akan dimanfaatkan sebagai material struktur sehingga pemanfaatannya bisa maksimal. Dalam penelitian ini, tanah Mediteran akan digunakan sebagai bahan substitusi pada komposisi semen yang akan digunakan dalam membuat beton dan dalam proses kerja penelitian ini menggunakan variasi 
substitusi tanah Mediteran dibandingkan dengan beton yang menggunakan semen biasa tanpa tanah Mediteran.

Dalam ilmu arsitektur penelitian ini termasuk hal baru yang seyogyanya akan memberikan manfaat kepada masyarakat, karena pembuatan beton normal dengan bahan utama semen yang disubstitusi tanah Mediteran ini dianggap perlu demi menghemat penggunaan atau mengurangi eksploitasi batu kapur di Indonesia secara massal.

\section{Metode Penelitian}

\section{Metode}

Metode penelitian yang digunakan dalam penelitian ini yaitu metode eksperimen. Menurut Sudjana (2004:19), metode penelitian eksperimen dapat diartikan sebagai berikut: "suatu metode yang mengungkap hubungan antara dua variabel atau lebih atau mencari pengaruh suatu variabel terhadap variabel lainnya." Metode eksperimen yang dilakukan pada penelitian ini yaitu dengan cara memberikan dua perlakuan berbeda terhadap subyek penelitian, berupa penggunaan 2 jenis semen yang berbeda pada pembuatan beton. Penggunaan semen ppc diberikan kepada kelompok eksperimen pertama dan penggunaan semen ppc yang sebagian komposisinya diganti tanah Mediteran diberikan kepada kelompok eksperimen kedua.

\section{Variabel Penelitian}

Menurut Sugiyono (2006), variabel penelitian adalah segala sesuatu yang ditetapkan oleh peneliti untuk dipelajari sehingga didapatkan sebuah informasi untuk diambil sebuah kesimpulan.
1. Variabel Terikat

Variabel terikat adalah variabel yang mempengaruhi atau menjadi akibat, karena adanya variabel bebas. Variabel terikat dalam penelitian ini adalah nilai slump beton, kekuatan mutu beton yakni kuat tekan dan kuat tarik beton yang menggunakan semen dengan substitusi dari bahan tanah Mediteran, dan berat jenis beton.

2. Variabel Bebas

Variabel bebas adalah variabel yang mempengaruhi timbulnya variabel terikat. Variabel bebas dalam penelitian ini adalah komposisi tanah Mediteran sebagai bahan pengganti sebagian semen yang sesuai dengan jumlah komposisi semen pada campuran beton pada umumnya. Usia beton yang diuji adalah pada hari ke 3, 7, 14 dan 28 hari.

3. Variabel Kontrol

Variabel kontrol adalah variabel konstan yang digunakan untuk membandingkan variabel lain. Variabel kontrol dalam penelitian ini adalah campuran material untuk beton, yaitu air, semen, agregat halus (pasir), agregat kasar (batu pecah), cara perawatan benda uji, umur benda uji, kadar udara dan temperature benda uji.

\section{Benda Uji}

Benda uji yang digunakan dalam penelitian ini berupa benda uji beton berbentuk silinder dengan diameter 10 $\mathrm{cm}$ dan tinggi $20 \mathrm{~cm}$. Total benda uji yang digunakan dalam penelitian ini adalah 45 benda uji dengan uraian metode dry curing pada presentase $0 \%$, $20 \%$ dan $40 \%$ tanah Mediteran masing-masing sebanyak 3 buah benda uji silinder untuk uji tekan umur tekan 3 hari, 7 hari, 14 hari dan 28 hari, serta 3 sampel untuk uji kuat tarik pada umur 28 hari. 
Alat dan Bahan

Dalam melakukan penelitian diperlukan alat dan bahan yang membantu kita dalam melakukan eksperimen terkait pembuatan beton. Penelitian ini menggunakan alat dan bahan sebagai berikut:

1. Alat

Alat yang digunakan berupa: timbangan, saringan, oven, cetakan, alat penggetar, kerucut Abrams, universal testing machine, molen, air meter concrete, vibrator, loyang, keranjang sampel, pyconemeter, ember, talam, mistar dan perojok besi.

2. Bahan

Bahan yang digunakan berupa: tanah Mediteran, semen, agregat halus, agregat kasar dan air.

\section{Tahapan dan Prosedur Penelitian}

Sebagai penelitian ilmiah, penelitian harus dilaksanakan dalam sistematika dan urutan yang jelas dan teratur sehingga hasilnya dapat dipertanggung jawabkan. Tahapan pelaksanaan dari penelitian ini secara garis besar dibagi dalam beberapa tahap, yaitu:

1. Tahap Persiapan

Tahap persiapan benda uji merupakan suatu tahapan dimana segala sesuatu yang berkaitan dengan pembuatan benda uji harus dipersiapkan. Tahapan ini berisi tentang persiapan alat, bahan, tempat, penelitian atau pemeriksaan bahan agregat kasar dan agregat halus, penentuan mix design sesuai SK. SNI. T-15-1990-03 dan teknis pelaksanaan.

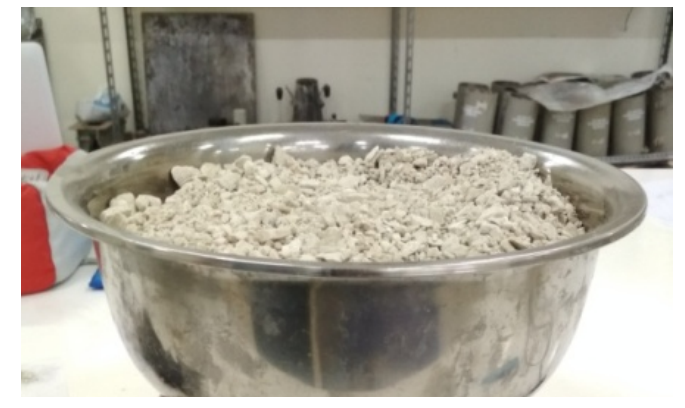

Gambar 1. Tanah Mediteran

Sumber: Hasil pengujian penulis, 2018

Tahap persiapan material tanah Mediteran dilakukan perlakuan sebagai berikut: Penggalian/quarrying diambil dari lokasi Kab. Jeneponto yang kemudian dibawa ke tempat pengumpulan bahan yaitu Laboratorium Struktur Fakultas Teknik yang disimpan ke dalam suatu wadah. Dalam pengumpulan bahan ini peneliti mengambil sampel seberat $10 \mathrm{~kg}$.
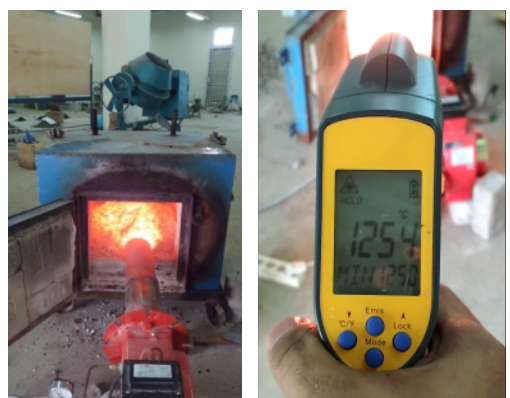

\section{Gambar 2. Pembakaran tanah Mediteran Sumber : Hasil pengujian penulis, 2018}

Tanah Mediteran yang berupa serpihan halus dipisahkan dari tanah yang berbentuk bongkahan batu dan dilakukan proses pembakaran secara terkontrol pada box fire iron machine dengan suhu $1200^{\circ} \mathrm{C}$ secara kontinu dan diaduk sesekali agar pembakarannya merata selama 120 menit. 


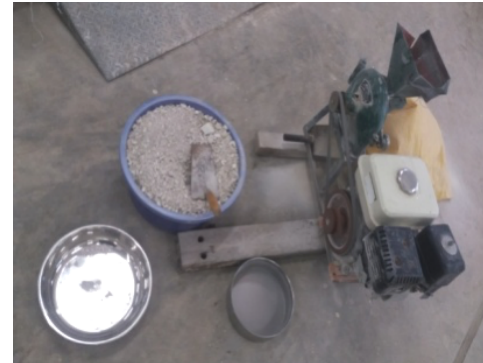

Gambar 3. Penggilingan tanah Mediteran Sumber: Hasil pengujian penulis, 2018

Setelah dibakar dan didinginkan selama 24 jam, tanah yang berbentuk bongkahan terlebih dahulu dilakukan penghalusan dan kemudian dilakukan penggilingan, sehingga tanah Mediteran mencapai kehalusan yang disyaratkan.

2. Tahap Pengumpulan Data

Data adalah segala fakta dan angka yang dapat dijadikan bahan menyusun suatu informasi, sedangkan informasi adalah hasil pengolahan data yang dipakai untuk suatu keperluan (Arikunto, 2002). Berikut tabel mengenai data yang dibutuhkan:

Tabel 2. Kebutuhan data

\begin{tabular}{|l|l|l|}
\hline No. & $\begin{array}{l}\text { Kebutuhan } \\
\text { Data }\end{array}$ & \multicolumn{1}{|c|}{ Hasil } \\
1. & $\begin{array}{l}\text { Data Sifat } \\
\text { Bahan }\end{array}$ & $\begin{array}{l}\text { Berat Jenis Bahan, } \\
\text { Sifat Kimiawi, Specific } \\
\text { Gravity } \\
\text { Saturated Surface Dry } \\
\text { (SSC), Kadar Resapan } \\
\text { Air }\end{array}$ \\
\hline 2. & $\begin{array}{l}\text { Mixed } \\
\text { Design }\end{array}$ & $\begin{array}{l}\text { Hasil Perancangan dan } \\
\text { Perhitungan Mixed } \\
\text { Design }\end{array}$ \\
\hline 3. & $\begin{array}{l}\text { Kekuatan } \\
\text { Mutu Beton }\end{array}$ & $\begin{array}{l}\text { Hasil Uji Kuat Tekan } \\
\text { dan Kuat Tarik Beton }\end{array}$ \\
\hline 4. & $\begin{array}{l}\text { Fresh } \\
\text { Concrete }\end{array}$ & $\begin{array}{l}\text { Kadar Udara, Slump } \\
\text { Test, Berat Unit (m }{ }^{3} \text { ), } \\
\text { dan temperatur }\end{array}$ \\
\hline
\end{tabular}

3. Tahap Pembuatan Benda Uji

Benda uji yang dibuat adalah beton normal dengan variasi perbedaan presentase kandungan semen dalam beton yang mana dilakukan substitusi terhadap tanah Mediteran sebesar $20 \%$ dan $40 \%$ dari komposisi semen. Dalam penelitian ini benda uji divariasikan menjadi dua macam mix design, yaitu dengan mengubah perbandingan presentase kandungan semen dalam beton. Pada pelaksanaannya pencampuran beton dilakukan dengan menggunakan molen (mesin pengaduk) hal ini bermaksud untuk mempermudah proses pengadukan dan membuat adukan akan lebih tercampur dengan baik.

Untuk mengontrol homogenitas suatu adukan, maka perlu dilakukan pengujian slump. Menurut SNI 1972:2008, pengujian slump adalah salah satu cara mengukur homogenitas dan tingkat kelecakan suatu adukan. Pengertian nilai slump sendiri adalah besarnya penurunan adukan yang ditinjau dari alat uji yaitu kerucut Abrams. Nilai slump berbanding lurus dengan kadar air adukan beton, sehingga akan berbanding terbalik dengan kekuatan beton. Setelah itu dilakukan pengujian kadar udara sehingga dapat diketahui hubungan antara kadar udara yang dikandung beton segar dengan sifat beton setelah mengeras terutama sifat daya tembus dan daya serap beton keras. Daya tembus permeabilitas adalah kemudahan air mengalir, sedangkan daya serap adalah kemampuan beton untuk mengikat air kedalam pori- pori. (SNI 033418-1994).

4. Tahap Perawatan Benda Uji

Setelah beton normal selesai dibuat, maka beton harus dirawat agar 
mempunyai kualitas yang baik. Pada tahap ini dilakukan perawatan secara kering (dry curing). Sebelum dilakukan perawatan, benda uji yang telah dibuat didiamkan selama 1 hari kemudian dikeluarkan dari cetakan silinder tersebut. Perawatan dilakukan dengan cara kering dengan meletakkan benda uji pada suhu ruangan bebas dan dilakukan pengujian pada saat yang telah ditentukan.

5. Tahap Pengujian Benda Uji

Pada tahap ini dilakukan pengujian pada silinder berdiameter $100 \mathrm{~mm}$ dengan tinggi $200 \mathrm{~mm}$ untuk kuat tekan beton pada umur 3 hari, 7 hari, 14 hari dan 28 hari dan kuat tarik diuji pada umur 28 hari. Pengujian ini dilakukan dengan menggunakan alat Universal Testing Machine kapasitas 1000 $\mathrm{KN}$.

Rumus untuk perhitungan kuat tekan beton menurut (SNI 19742011) adalah:

$$
\mathbf{F}_{\mathbf{c}}=\frac{\mathbf{P}}{\mathbf{A}}
$$

Dengan:

Fc : Kuat tekan beton $\left(\mathrm{N} / \mathrm{mm}^{2}\right)$

$\mathrm{P}$ : Beban maksimum (N)

A : Luas penampang benda uji $\left(\mathrm{mm}^{2}\right)$

Kuat tarik dengan uji belah silinder dapat ditentukan dengan persamaan (SNI 03-2491-2002):

$$
\mathrm{F}_{\mathrm{ct}}=\frac{2 P}{\pi L D}
$$

Dimana:

$$
\begin{aligned}
\text { Fct }= & \begin{array}{l}
\text { Kuat Tarik Belah Beton } \\
\left(\mathrm{N} / \mathrm{mm}^{2}\right)
\end{array} \\
\mathrm{P}= & \begin{array}{l}
\text { Beban pada Waktu Belah } \\
(\mathrm{N})
\end{array} \\
\mathrm{L}= & \begin{array}{l}
\text { Panjang Benda Uji Silinder } \\
(\mathrm{mm})
\end{array}
\end{aligned}
$$

$$
\mathrm{D}=\underset{(\mathrm{mm})}{\text { Diameter Benda Uji Silinder }}
$$

\section{Hasil dan Pembahasan}

\section{Proporsi Campuran (Mix Design)}

Hal yang harus diperhatikan sebelum melakukan pengecoran atau membuat benda uji adalah menentukan proporsi campurannya. Dalam penelitian ini material yang dibutuhkan untuk membuat beton modifikasi antara lain dapat dilihat dari detail perincian kebutuhan material per $1 \mathrm{~m}^{3}$ :

Tabel 3. Komposisi kebutuhan material per $1 \mathbf{m}^{3}$

\begin{tabular}{|l|l|l|l|l|}
\hline No & $\begin{array}{r}\text { Jenis } \\
\text { Beton } \\
\text { Material }\end{array}$ & $\begin{array}{c}\text { Beton } \\
\text { Normal } \\
\text { Tanah } \\
\text { Mediteran } \\
20 \%\end{array}$ & $\begin{array}{c}\text { Beton } \\
\text { Tanah } \\
\text { Mediteran } \\
40 \%\end{array}$ \\
\hline 1 & Air (kg) & 205.00 & 205.00 & 205.00 \\
\hline 2 & $\begin{array}{l}\text { Semen } \\
(\mathrm{kg})\end{array}$ & 375.00 & 300.00 & 225.00 \\
\hline 3 & Udara & - & - & - \\
\hline 4 & Pasir $(\mathrm{kg})$ & 699.00 & 699.00 & 699.00 \\
\hline 5 & $\begin{array}{l}\text { Kerikil } \\
(\mathrm{kg})\end{array}$ & 1071.0 & 1071.00 & 1071.00 \\
\hline 6 & $\begin{array}{l}\text { Tanah } \\
\text { Mediteran } \\
(\mathrm{kg})\end{array}$ & 0 & 75.00 & 150.00 \\
\hline
\end{tabular}

Sumber: Hasil perhitungan penulis, 2017

Untuk detail perincian kebutuhan material setiap 1 silinder per $\mathrm{m}^{3}$, berikut rinciannya:

Tabel 4. Komposisi kebutuhan material per 1 silinder $\mathbf{m}^{3}$

\begin{tabular}{|l|l|l|l|l|}
\hline No & $\begin{array}{r}\text { Jenis } \\
\text { Beton } \\
\text { Material }\end{array}$ & $\begin{array}{l}\text { Beton } \\
\text { Normal }\end{array}$ & $\begin{array}{c}\text { Beton } \\
\text { Tanah } \\
\text { Mediteran } \\
20 \%\end{array}$ & $\begin{array}{l}\text { Beton } \\
\text { Tanah } \\
\text { Mediteran } \\
40 \%\end{array}$ \\
\hline 1 & Air (kg) & 0.33 & 0.33 & 0.33 \\
\hline 2 & $\begin{array}{l}\text { Semen } \\
(\mathrm{kg})\end{array}$ & 0.60 & 0.48 & 0.36 \\
\hline 3 & Udara & - & - & - \\
\hline 4 & Pasir (kg) & 1.12 & 1.12 & 1.12 \\
\hline 5 & $\begin{array}{l}\text { Kerikil } \\
(\mathrm{kg})\end{array}$ & 1.71 & 1.71 & 1.71 \\
\hline 6 & $\begin{array}{l}\text { Tanah } \\
\text { Mediteran } \\
(\mathrm{kg})\end{array}$ & 0 & 0.12 & 0.24 \\
\hline
\end{tabular}

Sumber: Hasil perhitungan penulis, 2017 


\section{Pengujian Slump}

Dalam penelitian ini hasil pengujian nilai slump di setiap macam campuran menghasilkan hasil yang berbeda-beda, adapun hasil pengujian slump akan disajikan pada tabel di bawah ini:

Tabel 5. Hasil pengujian slump

\begin{tabular}{|c|c|}
\hline Jenis Beton & Nilai Slump \\
\hline Beton Normal & $12 \mathrm{~cm}$ \\
\hline $\begin{array}{c}\text { Beton + Tanah Mediteran } \\
20 \%\end{array}$ & $11 \mathrm{~cm}$ \\
\hline $\begin{array}{c}\text { Beton + Tanah Mediteran } \\
40 \%\end{array}$ & $10.85 \mathrm{~cm}$ \\
\hline
\end{tabular}

Sumber: Hasil pengujian penulis, 2018

Dari penelitian ini dapat diambil kesimpulan bahwa semakin besar penambahan dengan substitusi tanah Mediteran pada semen sebagai bahan campuran beton maka nilai workability/ kelecakan beton semakin menurun, dibuktikan dengan kecilnya nilai slump pada beton tanah Mediteran presentasi $20 \%$ yaitu 11 dan beton tanah Mediteran presentasi $40 \%$ yaitu $10.85 \mathrm{~cm}$ dibandingkan beton normal yaitu $12 \mathrm{~cm}$.

Hal ini disebabkan karena kemampuan tanah Mediteran dalam mengikat bahan-bahan agregat halus dan kasar lebih rendah dibandingkan dengan kemampuan pasta semen secara keseluruhan mengikat agregat.

\section{Berat Satuan Benda Uji}

Pemeriksaan berat satuan beton dilakukan sampai beton berumur 28 hari untuk melihat pengaruh substitusi tanah Mediteran terhadap bobot beton berdasarkan variasi masing-masing persentase komposisi. Adapun hasil pengujian berat satuan beton rata-rata dapat dilihat pada tabel berikut ini:

Tabel 6. Hasil pengujian berat rata-rata

\begin{tabular}{|c|l|l|l|}
\hline $\begin{array}{c}\text { Presentasi } \\
\text { Tanah } \\
\text { Mediteran }\end{array}$ & $\begin{array}{c}\text { Berat } \\
\text { Benda } \\
\text { Uji (Kg) }\end{array}$ & $\begin{array}{c}\text { Berat Jenis } \\
\text { Benda Uji } \\
\left(\mathrm{Kg} / \mathrm{m}^{3}\right)\end{array}$ & $\begin{array}{l}\text { Reduksi } \\
(\%)\end{array}$ \\
\hline $0 \%$ & 3.640 & 2,318 & 0 \\
\hline $20 \%$ & 3.500 & 2,229 & 3.84 \\
\hline $40 \%$ & 3.420 & 2,178 & 6.04 \\
\hline \multicolumn{3}{|l|}{ Sumber : Hasil pengujian penulis, 2018 } \\
\hline
\end{tabular}

\section{Bobot Beton}

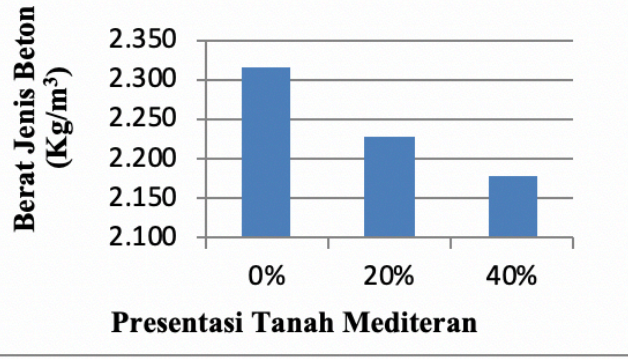

Gambar 4. Grafik hubungan persentase tanah Mediteran terhadap bobot isi beton Sumber : Hasil pengujian penulis, 2018

Dari tabel 6 dan gambar 4 dapat disimpulkan bahwa semakin besar penambahan tanah Mediteran pada campuran beton, maka berat satuan beton akan semakin ringan. Berat satuan beton tanah Mediteran 20\% dan $40 \%$ lebih dari $1900 \mathrm{~kg} / \mathrm{m}^{3}$, sehingga dapat dikategorikan sebagai beton normal. (SNI 03-2847-2002).

\section{Pengujian Kuat Tekan}

Pada beton yang telah mengeras (setting) dilakukan pengetesan kuat tekan beton pada hari ke 3, 7, 14 dan 28 hari yang disajikan pada tabel berikut: 
Tabel 7. Hasil uji kuat tekan

\begin{tabular}{|l|c|c|c|c|c|c|c|c|c|}
\hline \multirow{2}{*}{ No } & \multirow{2}{*}{ Jenis Beton } & \multicolumn{3}{|c|}{$\begin{array}{c}\text { Kuat Tekan Beton Rata- } \\
\text { Rata (MPa) }\end{array}$} & \multicolumn{3}{c|}{$\begin{array}{c}\text { Kuat Tekan Beton Rata-Rata } \\
\left(\text { Kgf/cm }{ }^{2}\right)\end{array}$} \\
\cline { 3 - 10 } & & 3 & 7 & 14 & 28 & 3 & 7 & 14 & 28 \\
\hline 1 & Beton Normal 0\% & 4.05 & 8.14 & 9.84 & 16.3 & 48.80 & 98.07 & 118.6 & 195.7 \\
\hline 2 & Beton T. Mediteran 20\% & 3.03 & 3.91 & 5.21 & 7.9 & 36.51 & 47.11 & 62.77 & 96.27 \\
\hline 3 & Beton T. Mediteran 40\% & 4.78 & 6.08 & 9.37 & 9.13 & 57.59 & 73.25 & 112.9 & 110 \\
\hline
\end{tabular}

Sumber : Hasil pengujian penulis, 2018

Berdasarkan data dari hasil uji kuat tekan beton, maka dapat disimpulkan bahwa terjadi peningkatan kuat tekan beton dengan substitusi tanah Mediteran pada perawatan kering seiring dengan bertambahnya komposisi tanah Mediteran dan umur beton. Hal ini disebabkan karena proses hidrasi pada pasta semen dan tanah Mediteran yang terus meningkat dan memperkuat ikatan antara material pada campuran beton.

Berikut adalah grafik hasil kuat tekan dibandingkan dengan umur beton dengan masing-masing komposisi tanah Mediteran pada perawatan kering (dry curing).

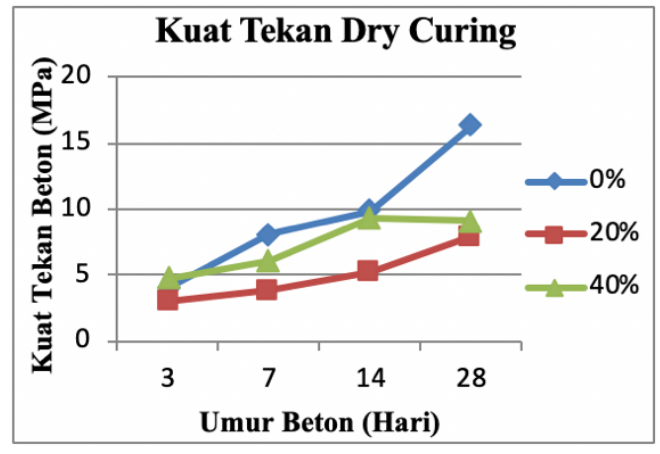

Gambar 5. Grafik hubungan kuat tekan beton dengan umur pengujian

Sumber: Hasil pengujian penulis, 2018

Dari grafik di atas, dilihat bahwa nilai kuat tekan untuk beton normal masih lebih tinggi dibandingkan dengan kuat tekan beton tanah Mediteran. Hal ini dapat terjadi karena diduga proses pengikatan antar material pada beton tanah Mediteran yang belum mampu melebihi kemampuan pengikatan dengan menggunakan semen secara keseluruhan karena adanya kadar tanah liat, pasir silica dan pasir besi pada semen biasa.

Selain itu, kekuatan tekan beton dengan komposisi tanah Mediteran 40\% lebih tinggi dibanding komposisi tanah Mediteran 20\% karena proses substitusi atau penambahan tanah Mediteran $\quad 20 \% \quad$ mengandung komposisi kimia yang lebih rendah dibandingkan unsur kimia pada komposisi semen yang dikeluarkan.

Berbeda dengan komposisi kimia pada tanah Mediteran 40\%, komposisi yang dikeluarkan dan yang ditambahkan hampir seimbang sehingga kuat tekannya juga hampir mendekati kuat tekan beton normal. 


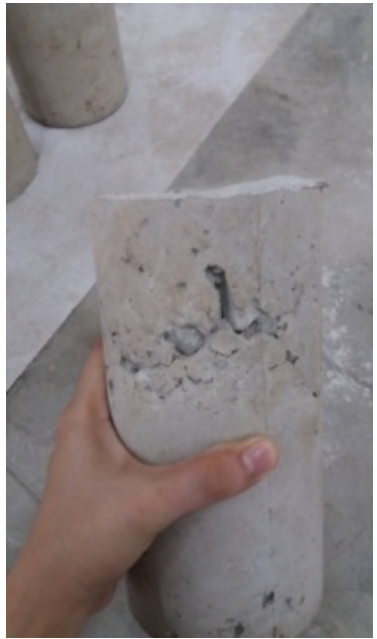

Gambar 6. Sampel beton yang berongga Sumber: Hasil pengujian penulis, 2018

Namun, pada hari ke 28 dari sampel 40\% tanah Mediteran kuat tekannya jika dibandingkan dengan kekuatan beton normal kekuatan belum mampu meningkatkan kuat tekan sebesar 20\% dari beton normal sesuai dengan harapan, bahkan terlihat menurun. Hal ini diduga terjadi karena adanya rongga udara pada sampel akibat pemadatan (compacting) yang kurang baik, sesuai dalam (Nugraha dan Antoni, 2007) mengatakan bahwa adanya rongga udara mengurangi kekuatan beton sehingga cenderung melemahkan sifat mekanisnya. Adanya rongga $1 \%$ volume, akan mengurangi kekuatan tekan sebesar 5\% sampai $6 \%$. Serta persebaran agregat kasar pada setiap sampel yang belum merata yang menyebabkan ada beberapa sampel yang memiliki nilai kuat tekan lebih baik dibandingkan dengan sampel lainnya akibat didiukung oleh volume agregat kasar yang lebih banyak.

Jadi, terdapat kemungkinan bahwa kuat tekan beton pada komposisi 40\% tanah Mediteran juga akan meningkat pada hari ke 28, sama halnya dengan beton tanah Mediteran 20\% bila tidak ada rongga pada silinder benda uji.

\section{Pengujian Kuat Tarik}

Pengujian kuat tarik belah beton menggunakan mesin UTM kapasitas $1000 \mathrm{KN}$ pada saat benda uji berumur 28 hari. Metode pengujian sama dengan kuat tekan, namun yang membedakan adalah posisi beton yang direbahkan dan meletakkan lempengan plat di atas beton agar pada saat pengujian, beban dapat terbagi rata.

Adapun hasil perhitungan kuat tarik belah dapat dilihat pada tabel di bawah ini:

Tabel 8. Hasil perhitungan kuat tarik beton umur 28 hari

\begin{tabular}{|c|c|c|}
\hline $\begin{array}{c}\text { Presentasi } \\
\text { Tanah } \\
\text { Mediteran } \\
(\%)\end{array}$ & $\begin{array}{c}\text { Umur } \\
\text { Pengujian } \\
\text { (Hari) }\end{array}$ & $\begin{array}{c}\text { Kuat Tarik } \\
\text { Beton Rata- } \\
\text { Rata (MPa) }\end{array}$ \\
\hline 0 & 28 & 1.34 \\
\hline 20 & 28 & 0.93 \\
\hline 40 & 28 & 1.31 \\
\hline
\end{tabular}

Sumber : Hasil pengujian penulis, 2018

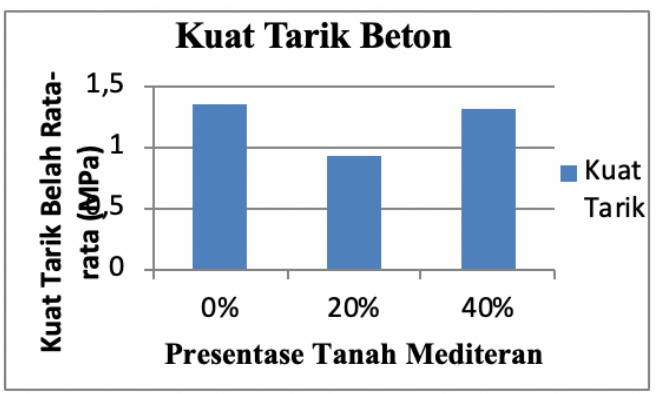

Gambar 7. Grafik hubungan kuat tarik beton dengan umur pengujian

Sumber : Hasil pengujian penulis, 2018

Dari tabel, grafik dan gambar di atas menunjukkan bahwa kuat tarik beton meningkat seiring dengan bertambahnya variasi komposisi tanah Mediteran. Semakin banyak tanah Mediterannya semakin tinggi pula kuat tariknya. Hal ini dapat terjadi karena pada komposisi tanah Mediteran 20\% proses ikatan matriks agregat, pasta 
semen dan tanah Mediteran yang kurang sempurna dan penyebaran (dipersion) agregat kasar yang tidak merata berbeda halnya komposisi tanah Mediteran 40\% yang terlihat merata sehingga proses pengikatannya juga hampir sempurna mendekati beton normal.

Sehingga, dapat disimpulkan bahwa nilai kuat tarik dari beton modifikasi tanah Mediteran baik 20\% maupun $40 \%$ hasilnya sangat baik karena telah melebihi standar ketetapan kuat tarik sesuai dalam Munaf, dkk. (2011) bahwa kekuatan tarik beton (ft) biasanya berkisar 0,05 sampai 0,1 dari nilai kuat tekannya.

\section{Kesimpulan}

Pengaruh dari substitusi tanah Mediteran pada campuran beton terhadap komposisi semen belum mampu meningkatkan kuat tekan beton secara maksimal dikarenakan kuat tekannya masih berada pada kisaran kuat tekan beton normal. Dari persentase substitusi yang diteliti yakni $20 \%$ dan $40 \%$ beton dengan kandungan tanah Mediteran sebanyak $40 \%$ menghasilkan nilai kuat tekan yang menghampiri kuat tekan beton tanpa penambahan tanah Mediteran maupun beton dengan persentase campuran lainnya.

Dari hasil uji tarik belah, diperoleh fakta bahwa semakin besar volume tanah Mediteran maka semakin tinggi kuat tarik belah yang dihasilkan dengan penurunan minimum terhadap beton normal sebesar $2 \%$ pada volume $40 \%$ tanah Mediteran. Dalam penelitian ini beton masih termasuk dalam jenis beton normal karena berat jenis betonnya masih diatas 1900 $\mathrm{kg} / \mathrm{m}^{3}$.

Berdasarkan hasil penelitian ini, maka diperlukan penelitian lebih lanjut pada beton tanah Mediteran untuk meningkatkan sifat mekanik beton yaitu kuat tekan dan kuat tarik belah beton.

\section{Daftar Pustaka}

Arikunto, S. (2002). Prosedur penelitian suatu pendekatan praktek. Jakarta: PT. Rineka Cipta.

Badan Standardisasi Nasional. (2011). SNI 1974:2011 Cara uji kuat tekan beton dengan benda uji silinder. Jakarta: Kementerian Pekerjaan Umum.

Badan Standardisasi Nasional. (2008). SNI 1972:2008 Cara uji slump beton. Jakarta: Kementerian Pekerjaan Umum.

Badan Standardisasi Nasional. (2002). SNI 03-2491-2002 Metode pengujian kuat tarik belah beton. Jakarta: Kementerian Pekerjaan Umum.

Badan Standardisasi Nasional. (2002). SNI 03-2847-2002 Tata cara perhitungan struktur beton untuk bangunan gedung. Jakarta: Kementerian Pekerjaan Umum.

Badan Standardisasi Nasional. (1994). SNI 03-3418-1994 Metode pengujian kandungan udara pada beton segar. Jakarta: Kementerian Pekerjaan Umum.

Madiadipoera, T. (1990). Bahan galian industri di Indonesia. Bandung: Direktorat Jendral Sumber Daya Mineral.

McCormac, J.C. (2000). Desain beton bertulang jilid 1. Jakarta: Erlangga.

Munaf, D.R., Suharwanto, dan Firdaus. (2011). Material semen dan beton (SI-487). Bandung: Penerbit ITB.

Nawy, Edward G. (1998). Beton bertulang: Suatu pendekatan dasar. Bandung: PT. Refika Aditama. 
Nugraha, P. dan Antoni. (2007).

Teknologi beton. Yogyakarta:

Andi Offset.

Samekto, W. dan Rahmadiyanto, C.

(2001). Teknologi beton.

Yogyakarta: Kanisius.

Sudjana, N. (2004). Dasar-dasar proses belajar mengajar.

Bandung: Sinar Baru

Algensindo.

Sugiyono. (2006). Metode penelitian kuantitatif, kualitatif dan $R \& D$. Bandung: Alfabeta.

Syarif, M., et al. (2018). Analysis of the physical properties of alternative cement made from recycled waste material. International Journal of Civil Engineering and Technology (IJCIET), Volume 9, Issue 9, September 2018, pp. 1441-1450. 